\title{
Timing in trace conditioning of the nictitating membrane response of the rabbit (Oryctolagus cuniculus): Scalar, nonscalar, and adaptive features
}

\author{
E. James Kehoe, ${ }^{1,3}$ Elliot A. Ludvig, ${ }^{2}$ and Richard S. Sutton ${ }^{2}$ \\ ${ }^{1}$ School of Psychology, University of New South Wales, Sydney, New South Wales 2052, Australia; ${ }^{2}$ Department of Computing \\ Sciences, University of Alberta, Edmonton, Alberta T6G 2E8, Canada
}

\begin{abstract}
Using interstimulus intervals (ISIs) of 125, 250, and 500 msec in trace conditioning of the rabbit nictitating membrane response, the offset times and durations of conditioned responses (CRs) were collected along with onset and peak latencies. All measures were proportional to the ISI, but only onset and peak latencies conformed to the criterion for scalar timing. Regarding the CR's possible protective overlap of the unconditioned stimulus (US), CR duration increased with ISI, while the peak's alignment with the US declined. Implications for models of timing and CR adaptiveness are discussed.
\end{abstract}

This experiment builds on recent analyses of the timing of conditioned responses (CRs) in the rabbit nictitating membrane (NM) preparation (Kehoe et al. 2008, 2009a,b). The theoretical aim of these studies was to inform models of NM conditioning, which assume that CR timing is mediated by a spectrum of microstimuli initiated by the conditioned stimulus (CS) (Desmond and Moore 1988; Grossberg and Schmajuk 1989; Gluck et al. 1990; Sutton and Barto 1990; Buonomano and Mauk 1994; Machado 1997; Kirkpatrick and Church 1998; Buhusi and Schmajuk 1999; Vogel et al. 2003; Ludvig et al. 2008, 2009). Their neural counterpart resides in activation across the cerebellar cortex (Buonomano and Mauk 1991; Moore and Choi 1997; Mauk et al. 2000), including the planar arrangement of Purkinje cells and their dendritic morphology (Ito 1984; Steuber and Willshaw 2004). In fact, interstimulus interval (ISI)-dependent activity has appeared in Purkinje cells (Jirenhed et al. 2007). This cerebellar activity ultimately drives the motor processes underpinning eyelid movement (Bartha and Thompson 1992; Lepora et al. 2007, 2009; Mavritsaki et al. 2007).

The first empirical aim of the present experiment was to determine whether CR timing is scalar in trace conditioning. In delay conditioning, CR timing is approximately scalar. Specifically, both the mean and variance of timing measures are proportional to the ISI between the onsets of the CS and unconditioned stimulus (US) (White et al. 2000; Kehoe et al. 2009a,b). However, the smallest ISI for these studies has been $200 \mathrm{msec}$. For shorter ISIs, the time course of CRs averaged across trials and subjects has appeared proportional to the ISI (Smith 1968; Dudeney et al. 2007), but it has not been determined precisely whether individual CRs in this range are scalar. Moreover, in other species, scalar timing has broken down at short intervals (Church et al. 1976; Fetterman and Killeen 1992).

The second empirical aim of the present experiment was to characterize the adaptive value of the CR. Whether or not CR timing follows a scalar rule, the value of an eyeblink CR to a species relies on an interplay between maintaining current vision (eyelid open) and protecting the eye for future vision (eyelid closed). If maintaining vision is the major priority, then the system might generate CRs with short durations. On the other hand, if

\section{${ }^{3}$ Corresponding author.}

E-mail j.kehoe@unsw.edu.au; fax 61-2-9385 3641.

Article is online at http://www.learnmem.org/cgi/doi/10.1101/lm.1942210. protection of the eye takes priority, then the CR might show a short latency, sharp closure, and long duration. In fact, inspection of averaged CRs suggests a compromise in which the CR is graded so that eyelid closure starts after the midpoint of the ISI and reaches its peak around the time of US delivery (e.g., Smith 1968; Kehoe and Joscelyne 2005; Joscelyne and Kehoe 2007). However, averaging across CRs and animals may blur the time courses of individual CRs. For the present experiment, the adaptive value of CRs was indexed by analyzing their overlap of the US on an individual basis.

Three groups of rabbits $(n=8)$ were trained with ISIs of 125 , 250 , and $500 \mathrm{msec}$, by pairing a $50-\mathrm{msec}$ tone CS $(1000-\mathrm{Hz}, 83-\mathrm{dB}$ SPL, C scale superimposed on white noise, 76-dB SPL, C scale) with a 50-msec electrotactile US (3-mA, 50-Hz AC current to the periorbital region of the eye). The intertrial interval was uniformly randomized over 50-70 sec. There were $16 \mathrm{~d}$, each containing 42 CS-US trials intermixed with 18 CS-alone trials, on which the time course of NM movement was recorded without intrusion by the unconditioned response (UR). During training, groups 125 and 500 each lost a rabbit due to eye infections.

The apparatus and procedures (Kehoe and Joscelyne 2005) were based on those of Gormezano (1966). The NM's position was sampled every 5 msec. The onset latency, peak latency, and offset time were computed for each CR on the test trials (cf. Church et al. 1994; Ludvig et al. 2007). Movements that exceeded a $0.50-\mathrm{mm}$ criterion were counted as CRs. The onset latency was the first point that NM movement exceeded $0.0625 \mathrm{~mm}$, and the peak latency was the point of maximum closure after CS onset (Marshall-Goodell et al. 1982). The offset time, marking the reopening of the $\mathrm{NM}$ after the $\mathrm{CR}$ peak, was the last point within an $1100-\mathrm{msec}$ interval that was $0.50 \mathrm{~mm}$ higher than the posttrial resting position, which was estimated using the average of the NM positions during the final $400 \mathrm{msec}$ of the 2000-msec observation interval following CS onset.

Statistical contrasts used $\alpha$ error $=0.05\left(\mathrm{O}^{\prime}\right.$ Brien and Kaiser 1985). Effect size was measured by partial $\eta^{2}\left(\eta_{\mathrm{p}}^{2}\right)$, which equals the explained variance: $\mathrm{SS}_{\text {effect }} /\left(\mathrm{SS}_{\text {effect }}+\mathrm{SS}_{\text {error }}\right)$ (Cohen 1973). Cohen (1988) classifies $\eta_{p}^{2} \geq 0.138$ to be a large effect.

Figure 1 depicts the magnitude and likelihood of NM movements across CS-alone trials. The top panels $(\mathrm{A}-\mathrm{C})$ plot the magnitude of the largest NM movement on each trial for all animals in each group, plotted on a $\log _{10}$ scale. 

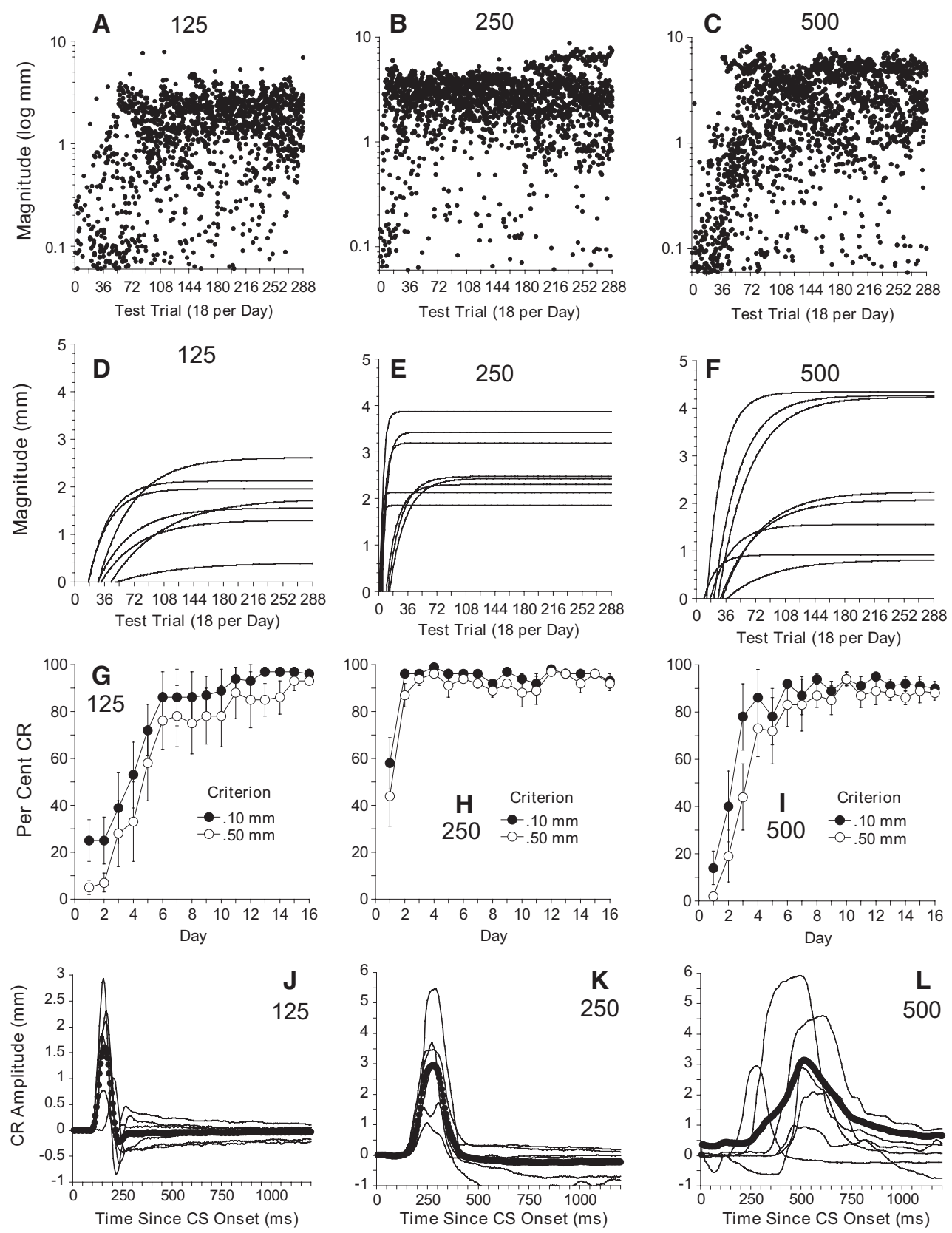

Figure 1. Panels $A-C$ plot the $\log _{10}$ magnitudes for each nictitating membrane (NM) movement for all animals in groups 125,250 , and 500 , respectively. Because there is no logarithm for zero, movements of zero magnitude are not plotted. Panels $D-F$ plot the best-fitting Weibull function for each animal in each group. Panels $G-I$ show the mean percentage of trials containing a conditioned response (CR) defined as NM movement that exceeded one of two criteria, specifically, $0.50 \mathrm{~mm}$ and $0.10 \mathrm{~mm}$. Panels $J-L$ plot the time course of CRs during a single CS-alone trial on day 16 for individual rabbits (thin lines) and their average (thick line). The vertical axes are adjusted to better expose the time course of the CRs.

To quantify the acquisition, panels $\mathrm{D}, \mathrm{E}$, and $\mathrm{F}$ show plots of Weibull curves fitted to each animal's magnitudes (Gallistel et al. 2004; Kehoe et al. 2008). Furthermore, panels G, H, and I show the mean percentage of trials containing a CR defined as movements that exceeded either (1) a conventional criterion of $0.50 \mathrm{~mm}$ or (2) a criterion of $0.10 \mathrm{~mm}$, the smallest movement that is largely uncontaminated by tiny spontaneous flutters $(<10 \%)$ (Kehoe et al. 2009a,b). Consistent with previous findings (Smith 1968; Smith et al. 1969; Kehoe and Macrae 2002), the 250-msec ISI produced the most rapid CR acquisition relative to the $125-\mathrm{msec}$ and 500-msec ISIs, smaller quadratic trend $F_{(1,19)}=6.95, P<0.05$, $\eta_{\mathrm{p}}^{2}=0.268$.

While the rate of acquisition was a quadratic function of ISI, $\mathrm{CR}$ timing was proportional to ISI. Panels $\mathrm{G}, \mathrm{H}$, and I plot the time course of CRs during a single CS-alone trial on day 16. The thin lines show the CRs of individual rabbits, while the thicker lines depict their average. As can be seen, as ISI was increased, the CRs became later, wider, and more variable.

Previous quantitative analyses of CR timing have primarily focused on the initiation of the CR (onset latency) and the 

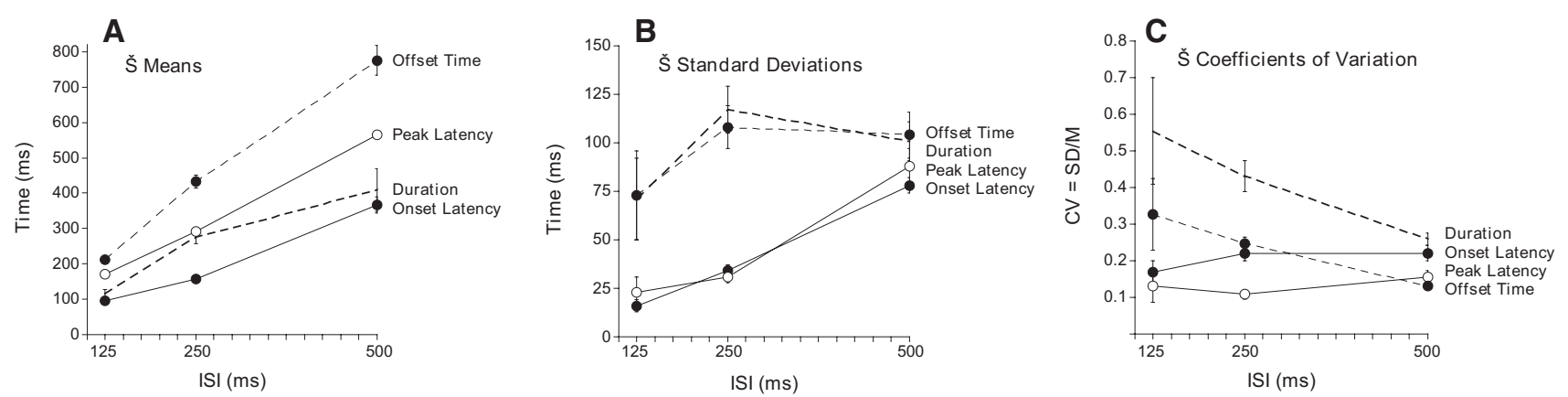

Figure 2. Panel $A$ shows the means for onset latency, peak latency, offset time, and duration as a function of ISI. Panel $B$ shows the SDs of these dependent variables. Panel $C$ shows the mean coefficient of variation (CV), which is the standard deviation (SD)/mean (M).

time of maximum closure (peak latency) (Schneiderman and Gormezano 1964; Schneiderman 1966; Smith 1968; Dudeney et al. 2007; Kehoe et al. 2009a,b). To more fully characterize the time course of each CR (0.50-mm criterion), its offset time, and its duration (offset time - onset latency) were also computed (cf. Lepora et al. 2007).

In Figure 2, panel A shows the means for all four timing measures as a function of ISI for days 13-16. These means all rose linearly across ISIs, smallest $F_{(1,19)}=30.62, P<0.01, \eta_{\mathrm{p}}^{2}=0.617$. With respect to variability in timing (panel B), the SDs for the onset and peak latencies showed a significant upward trend, smaller $F_{(1,19)}=42.04, P<0.01, \eta_{\mathrm{p}}^{2}=0.689$. However, the SDs for the CR offset time and CR duration appeared constant across ISIs; any apparent differences were not statistically significant $(P s>0.05)$.

When means and SDs grow in the same proportion across ISIs, they yield a constant coefficient of variation $(\mathrm{CV}=\mathrm{SD} / \mathrm{M})$, which indicates that timing is scalar (Gibbon 1977). A previous examination of delay NM conditioning revealed that, for ISIs of 250, 500, and $1000 \mathrm{msec}$, the CVs for onset latency, but especially peak latency, were constant (Kehoe et al. 2009b). In the present experiment (panel C), the CVs for the onset and peak latencies appeared constant across ISIs (Ps $>0.05)$. However, the CVs for offset time and duration deviated strongly from the scalar criterion, showing significant downward trends, smaller $F_{(1,19)}=$ 5.73, $P<0.05, \eta_{\mathrm{p}}^{2}=0.232$.

To index the CR's adaptive value, Figure 3 shows the mean percentage of CS-alone test trials on which the CR overlapped the period occupied by the 50-msec US on CS-US trials. In brief, the degree of CR-US overlap depended on the specific index:

1. The least stringent index-any overlap-required only that any portion of a CR between its onset and offset overlapped the US. For example, if a CR's onset occurred even $5 \mathrm{msec}$ before the end of the US, an overlap was counted. For this index, all three groups showed at least 95\% overlap, but nevertheless with a significant decline across ISIs, $F_{(1,19)}=17.48, P<$ $0.01, \eta_{p}^{2}=0.462$.

2. A more stringent index-total overlap—required that the CR's duration encompass the entire 50-msec US interval. This criterion also yielded a high overall likelihood of overlap (88\%), but with a distinctive pattern. Specifically, group 125 showed significantly fewer overlaps than the other two groups, smaller $F_{(1,19)}=9.68, P<0.01, \eta_{\mathrm{p}}^{2}=0.337$.

3. Another more stringent index-peak near US-required that the CR peak occur within an time window starting $50 \mathrm{msec}$ before the time of US onset and ending 50 msec after US offset. This criterion yielded a high overall likelihood of overlap (87\%) that declined over ISIs, $F_{(1,19)}=46.52, P<0.01, \eta_{\mathrm{p}}^{2}=0.710$.
4. The most stringent index — peak during US—required that the CR peak occur during the US period. This criterion yielded the least overall overlap (47\%), plus a pronounced decline across ISIs, $F_{(1,19)}=49.99, P<0.01, \eta_{\mathrm{p}}^{2}=0.725$.

As noted previously, the CR's time course appears to balance maintaining current vision versus protecting the eye. This compromise involves two features that adapt the CR's time course to the warning period provided by the ISI. First, the peak of the NM closure tracked the time of US delivery. Second, as the accuracy of the peak placement declined across ISIs, the CR duration increased, maintaining some overlap with the US.

These findings provide an opportunity to refine models of CR acquisition and timing. These models have generally concerned primarily the method by which the passage of time since CS onset is represented in a spectrum of microstimuli, whose neural counterparts reside in cerebellar pathways (e.g., Buonomano and Mauk 1991; Moore and Choi 1997; Mauk et al. 2000; Lepora et al. 2010). Some models include CR generation rules that take account of the neural and mechanical lags between cerebellar output and movement of the NM (e.g., Bartha and Thompson 1992; Lepora et al. 2009). By combining these lags plus delays in the cerebellar-olivary feedback loop (see below), it is possible to model more accurately the entire time course of the CR, including systematic delays in the CR peak relative to the US (Lepora et al. 2010).

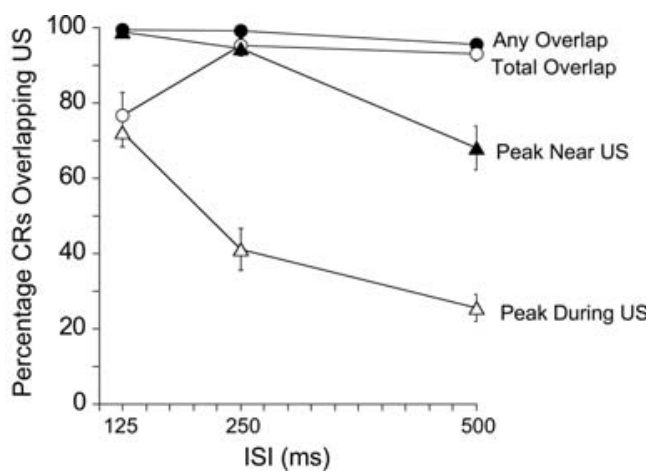

Figure 3. The mean percentage of CRs on CS-alone test trials that overlapped the time of US delivery, according to four indices of increasing stringency: (1) any overlap by any portion of the CR; (2) total overlap, for which the duration of the CR encompassed the entire 50-msec US duration; (3) peak near US, for which the CR peak occurred within a period 50 msec before or after the US; and (4) peak during US, for which the CR peak coincided exactly with the 50 -msec US duration. 
Sitting between CS input and CR output is the learning mechanism. At a conceptual level, the learning mechanism is usually described in terms of an error-correction rule, in which the increment in associative strength is proportional to the discrepancy between (1) the current associative weight activated by a CS, serving as a prediction of the US, and (2) the actual US (Rescorla and Wagner 1972; Sutton and Barto 1981). Thus, as this prediction better approximates US occurrence, the increments in associative strength progressively diminish. In the neural pathways for NM conditioning, the error-correction computation relies on an inhibitory feedback loop. Specifically, US input to the cerebellum rises through the inferior olive and climbing fibers. Consistent with an error-correction rule, the US input is progressively inhibited by the output of the cerebellar cortex via deep nuclei to the inferior olive (Yeo et al. 1986; Sears and Steinmetz 1991; Hesslow and Ivarsson 1996; Bengtsson and Hesslow 2006). In the present results, the negatively accelerated learning curves shown in Figure 1 are consistent with this errorcorrection process.

The spectral encoding of the CS in combination with an error-correction rule allows the CR's time course to be shaped by the intensities of the microstimuli. The microstimuli that are most intense at the time of the US gain the greatest associative strength. Conversely, less intense microstimuli gain less associative strength. Subsequently, the magnitude of the NM movement at each moment following CS depends on a summation of the associative strengths in proportion to intensities of the current microstimuli. In this way, the CR comes to be initiated before the US and reaches its peak near US onset, although with some lags (Lepora et al. 2010).

This approach to explaining the time course of the CR-spectral encoding plus error correction-differs dramatically from older accounts of response shaping (Boneau 1958; Prokasy 1965; Perkins 1968; Kimmel and Burns 1975). These older accounts presume that the acquisition and timing of the CR depends directly on the instrumental ability of an eyelid closure to attenuate the US. For a US that has a physical impact on the eye, such as an airpuff, this type of account has face validity. However, where the US has an impact around the eye, like the electrotactile US used in this experiment, the face validity of an instrumental hypothesis becomes increasingly speculative, and in any event, face validity is hardly sound support for any hypothesis. Empirically, when explicit avoidance contingencies for NM closure have been implemented, the results were opposite to an instrumental hypothesis. Specifically, response-contingent reductions in US intensity, including complete elimination, reduced the rate and asymptote of CR acquisition (Coleman 1975). Conversely, response-contingent increases in US intensity- "punishment"-tended to increase the rate of CR acquisition (Gormezano and Coleman 1973). Conditioning was thus related to the mean frequency and intensity of the US presentations, rather than the contingencies.

Learning based on errors in predicting the US, as implemented in the cerebellar-olivary feedback loop, has at least three advantages over learning based on the success of eyelid closure in attenuating the US. First, prediction-based learning can capitalize on any impact near the eye, whether or not it could be attenuated by eyelid closure. By using near-misses as well as hits on the eye, prediction-based learning can take advantage of a larger number of events, for example, strikes from brush and grit, which would be distributed around the eye. Second, prediction-based learning can occur prior to any attenuation of the US. In contrast, learning based on instrumental attenuation can only start after the random emission of an eyelid closure that happens to overlap and attenuate the US, in the manner of operant conditioning. Third, prediction-based learning can occur even when there are failures in CR-US overlap. In the present study, all three groups, including group 125, achieved high CR likelihoods even though CR-US overlap was rarely maximal, even asymptotically.

\section{Acknowledgments}

The apparatus and procedures were approved under Australian ethics legislation. Preparation of this manuscript was supported by the Informatics Circle of Research Excellence (iCORE), Alberta, Canada.

\section{References}

Bartha GT, Thompson RF. 1992. Control of rabbit nictitating membrane movements II. Analysis of the relation of motoneuron activity to behavior. Biol Cybern 68: 145-154.

Bengtsson F, Hesslow G. 2006. Cerebellar control of the inferior olive. Cerebellum 5: 7-14.

Boneau CA. 1958. The interstimulus interval and the latency of the conditioned eyelid response. J Exp Psychol 56: 464-471.

Buhusi CV, Schmajuk NA. 1999. Timing in simple conditioning and occasion setting: A neural network approach. Behav Processes 45: $33-57$.

Buonomano DV, Mauk MD. 1991. Neural network based on the circuitry of the cerebellum simulates the timing of motor responses. Abstr Soc Neurosci 17: 870

Buonomano DV, Mauk MD. 1994. Neural network model of the cerebellum: Temporal discrimination and the timing of motor responses. Neural Comput 6: 38-55.

Church RM, Getty DJ, Lerner ND. 1976. Duration discrimination in rats. I Exp Psychol Anim Behav Process 2: 303-312.

Church RM, Meck WH, Gibbon J. 1994. Application of scalar timing theory to individual trials. J Exp Psychol Anim Behav Process 20: 135-155.

Cohen J. 1973. Eta-squared and partial eta-squared in fixed factor ANOVA designs. Educ Psychol Meas 33: 107-112.

Cohen J. 1988. Statistical power analysis for the behavioral sciences, $2 \mathrm{nd}$ ed. Erlbaum, Hillsdale, NJ.

Coleman SR. 1975. Consequences of response-contingent change in unconditioned stimulus intensity upon the rabbit (Oryctolagus cuniculus) nictitating membrane response. J Comp Physiol Psychol 88: 591-595.

Desmond JE, Moore JW. 1988. Adaptive timing in neural networks: The conditioned response. Biol Cybern 58: 405-415.

Dudeney JE, Olsen KN, Kehoe EJ. 2007. Time-specific extinction and recovery of the rabbit's (Oryctolagus cuniculus) conditioned nictitating membrane response using mixed interstimulus intervals. Behav Neurosci 121: 808-813.

Fetterman JG, Killeen PR. 1992. Time discrimination in Columba livia and Homo sapiens. J Exp Psychol Anim Behav Process 18: 80-94.

Gallistel CR, Fairhurst S, Balsam PD. 2004. The learning curve: Implications of a quantitative analysis. Proc Natl Acad Sci 101: 13124-13131.

Gibbon J. 1977. Scalar expectancy theory and Weber's law in animal timing. Psychol Rev 84: 279-325.

Gluck MA, Reifsnider ES, Thompson RF. 1990. Adaptive signal processing and the cerebellum: Models of classical conditioning and VOR adaptation. In Neuroscience and connectionist theory (ed. MA Gluck, DE Rumelhart), pp. 131-185. Erlbaum, Hillsdale, NJ.

Gormezano I. 1966. Classical conditioning. In Experimental methods and instrumentation in psychology (ed. JB Sidowski), pp. 385-420. McGraw-Hill, New York.

Gormezano I, Coleman SR. 1973. The law of effect and CR contingent modification of the UCS. Cond Reflex 8: 41-56.

Grossberg S, Schmajuk NA. 1989. Neural dynamics of adaptive timing and temporal discrimination during associative learning. Neural Netw 2: 79-102.

Hesslow G, Ivarsson M. 1996. Inhibition of the inferior olive during conditioned responses in the decerebrate ferret. Exp Brain Res 110: 36-46.

Ito M. 1984. The cerebellum and neural control. Raven Press, New York.

Jirenhed D-A, Bengtsson F, Hesslow G. 2007. Acquisition, extinction, and reacquisition of a cerebellar cortical memory trace. J Neurosci 27: 2493-2502.

Joscelyne A, Kehoe EJ. 2007. Time and stimulus specificity in extinction of the conditioned nictitating membrane response in rabbit (Oryctolagus cuniculus). Behav Neurosci 121: 50-62.

Kehoe EJ, Joscelyne A. 2005. Temporally specific extinction of conditioned responses in the rabbit (Oryctolagus cuniculus) nictitating membrane preparation. Behav Neurosci 119: 1011-1022. 
Kehoe EJ, Macrae M. 2002. Fundamental behavioral methods and findings in classical conditioning. In A neuroscientist's guide to classical conditioning (ed. JW Moore), pp. 171-231. Springer, New York.

Kehoe EJ, Ludvig EA, Dudeney JE, Neufeld J, Sutton RS. 2008. Magnitude and timing of nictitating membrane movements during classical conditioning of the rabbit (Oryctolagus cuniculus). Behav Neurosci 122: 471-476.

Kehoe EJ, Ludvig EA, Sutton RS. 2009a. Magnitude and timing of CRs in delay and trace classical conditioning of the nictitating membrane response of the rabbit (Oryctolagus cuniculus). Behav Neurosci 123: $1095-1101$.

Kehoe EJ, Olsen KN, Ludvig EA, Sutton RS. 2009b. Scalar timing varies with response magnitude in classical conditioning of the nictitating membrane response of the rabbit (Oryctolagus cuniculus). Behav Neurosci 123: $212-217$.

Kimmel HD, Burns RA. 1975. Adaptational aspects of conditioning. In Handbook of learning and cognitive processes: Vol 2. Conditioning and behavior theory (ed. WK Estes), pp. 99-138. Erlbaum, Hillsdale, NJ.

Kirkpatrick K, Church RM. 1998. Are separate theories of conditioning and timing necessary? Behav Processes 44: 163-182.

Lepora NF, Mavritsaki E, Porrill J, Yeo CH, Evinger C, Dean P. 2007. Evidence from retractor bulbi EMG for linearized motor control of conditioned nictitating membrane responses. J Neurophysiol 98: 2074-2088.

Lepora NF, Porrill J, Yeo CH, Evinger C, Dean P. 2009. Recruitment in retractor bulbi muscle during eyeblink conditioning: EMG analysis and common-drive model. J Neurophysiol 102: 2498-2513.

Lepora N, Porrill J, Yeo C, Dean P. 2010. Sensory prediction or motor control? Application of Marr-Albus type models of cerebellar function to classical conditioning. Front Comput Neurosci 4: 140.

Ludvig EA, Conover K, Shizgal P. 2007. The effects of reinforcer magnitude on timing in rats. J Exp Anal Behav 87: 201-218.

Ludvig EA, Sutton RS, Kehoe EJ. 2008. Stimulus representation and the timing of reward-prediction errors in models of the dopamine system. Neural Comput 20: 3034-3054.

Ludvig EA, Sutton RS, Verbeek EL, Kehoe EJ. 2009. A computational model of hippocampal function in trace conditioning. Adv Neural Inf Process Syst (NIPS-08) 21: 993-1000.

Machado A. 1997. Learning the temporal dynamics of behavior. Psychol Rev 104: $241-265$

Marshall-Goodell B, Schreurs BG, Gormezano I. 1982. Ruler vs. the Apple II/FIRST system analysis of analog signals in classical conditioning. Behav Res Methods Instrum 14: 519-525.

Mauk MD, Medina JF, Nores WL, Ohyama T. 2000. Cerebellar function: Coordination, learning or timing? Curr Biol 10: R522-R525.

Mavritsaki E, Lepora N, Porrill J, Yeo CH, Dean P. 2007. Response linearity determined by recruitment strategy in detailed model of nictitating membrane control. Biol Cybern 96: 39-57.
Moore JW, Choi J-S. 1997. Conditioned response timing and integration in the cerebellum. Learn Mem 4: 116-129.

O'Brien RG, Kaiser MK. 1985. MANOVA method for analyzing repeated measures designs: An extensive primer. Psychol Bull 97: 316-333.

Perkins CC. 1968. An analysis of the concept of reinforcement. Psychol Rev 75: $155-172$.

Prokasy WF. 1965. Classical eyelid conditioning: Experimenter operations, task demands, and response shaping. In Classical conditioning: A symposium (ed. WF Prokasy), pp. 208-225. Appleton-Century-Crofts, New York.

Rescorla RA, Wagner AR. 1972. A theory of Pavlovian conditioning: Variations in the effectiveness of reinforcement and nonreinforcement. In Classical conditioning II (ed. AH Black, WF Prokasy), pp. 64-99. Appleton-Century-Crofts., New York.

Schneiderman N. 1966. Interstimulus interval function of the nictitating membrane response underlying trace versus delay conditioning. J Comp Physiol Psychol 62: 397-402.

Schneiderman N, Gormezano I. 1964. Conditioning of the nictitating membrane of the rabbit as a function of CS-US interval. J Comp Physiol Psychol 57: 188-195.

Sears LL, Steinmetz JE. 1991. Dorsal accessory inferior olive activity diminishes during acquisition of the rabbit classically conditioned eyelid response. Brain Res 545: $114-122$.

Smith MC. 1968. CS-US interval and US intensity in classical conditioning of the rabbit's nictitating membrane response. J Comp Physiol Psychol 66: $679-687$

Smith MC, Coleman SR, Gormezano I. 1969. Classical conditioning of the rabbit's nictitating membrane response at backward, simultaneous, and forward CS-US intervals. J Comp Physiol Psychol 69: 226-231.

Steuber V, Willshaw D. 2004. A biophysical model of synaptic delay learning and temporal pattern recognition in a cerebellar Purkinje cell. J Comput Neurosci 17: 149-164.

Sutton RS, Barto AG. 1981. Toward a modern theory of adaptive networks: Expectation and prediction. Psychol Rev 88: 135-171.

Sutton RS, Barto AG. 1990. Time-derivative models of Pavlovian reinforcement. In Learning and computational neuroscience (ed. M Gabriel, JW Moore), pp. 497-537. MIT Press, Cambridge, MA.

Vogel EH, Brandon SE, Wagner AR. 2003. Stimulus representation in SOP: II. An application to inhibition of delay. Behav Processes 62: 27-48.

White NE, Kehoe EJ, Choi J-S, Moore JW. 2000. Coefficients of variation in timing of the classically conditioned eyeblink in rabbits. Psychobiol 28: $520-524$.

Yeo CH, Hardiman MJ, Glickstein M. 1986. Classical conditioning of the nictitating membrane response of the rabbit. IV. Lesions of the inferior olive. Exp Brain Res 63: 81-92.

Received July 16, 2010; accepted in revised form September 21, 2010. 


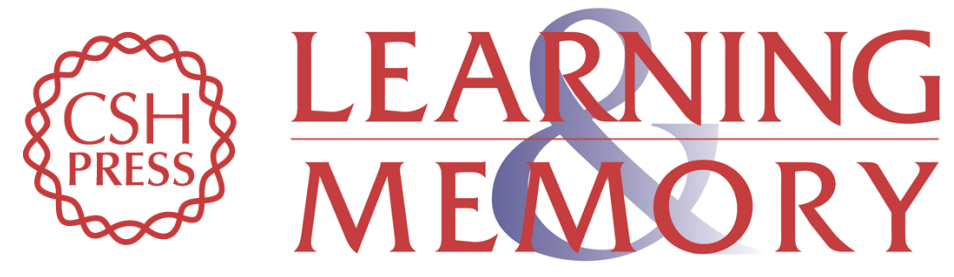

\section{Timing in trace conditioning of the nictitating membrane response of the rabbit ( Oryctolagus cuniculus): Scalar, nonscalar, and adaptive features}

E. James Kehoe, Elliot A. Ludvig and Richard S. Sutton

Learn. Mem. 2010, 17:

Access the most recent version at doi: $10.1101 / \mathrm{lm} .1942210$

References This article cites 48 articles, 3 of which can be accessed free at: http://learnmem.cshlp.org/content/17/12/600.full.html\#ref-list-1

License

Email Alerting

Receive free email alerts when new articles cite this article - sign up in the box at the Service top right corner of the article or click here. 